\title{
Effects of intrajugular glucose infusion on feed intake, milk yield, and metabolic responses of early postpartum cows fed diets varying in protein and starch concentration
}

\author{
W. E. Brown and M. S. Allen ${ }^{1}$ \\ Department of Animal Science, Michigan State University, East Lansing 48824
}

\begin{abstract}
Effects of glucose infusion on feed intake, milk production, and metabolic responses of early postpartum cows fed diets varying in starch and protein concentration were evaluated by utilizing a randomized complete block design with a $2 \times 2$ factorial arrangement of treatments. Twenty-four multiparous Holstein cows were blocked by body condition score and 305-d mature-equivalent milk yield and randomly assigned at calving to 1 of 4 treatments. Treatments were continuous intrajugular infusion of glucose (GI) or isotonic saline (SI), and diets containing high starch, low crude protein (HSLP) or high crude protein, low starch (HPLS) concentrations. Treatments were initiated at the first scheduled feeding following parturition and lasted $12 \mathrm{~d}$. The GI reduced cumulative dry matter intake and tended to reduce daily dry matter intake and meal size for HPLS but not HSLP compared with SI. The GI increased cumulative milk yield by $39 \mathrm{~kg} / 12$ d compared with SI by increasing it for HSLP but not HPLS. The HPLS treatment tended to increase loss of body condition from 0.65 to 0.82 body condition score units/12 d compared with HSLP. Consistent with this, HPLS increased plasma concentrations of nonesterified fatty acids, $\beta$-hydroxybutyrate, liver triglyceride, milk fat concentration and yield, $3.5 \%$ fat-corrected milk, and milk urea nitrogen compared with HSLP. Overall, the GI-HPLS treatment reduced feed intake by reducing meal size. The GI-HPLS may have reduced meal size by the independent or additive effects of (1) decreasing hepatic gluconeogenesis and promoting oxidation of acetyl coenzyme A (CoA), (2) elevated plasma nonesterified fatty acids from HPLS increasing the pool of acetyl CoA available to be oxidized, and (3) the HPLS diet increasing urea synthesis, which also provides the tricarboxylic acid cycle intermediate fumarate to promote oxidation of acetyl CoA.
\end{abstract}

Received January 28, 2013.

Accepted July 13, 2013.

${ }^{1}$ Corresponding author: allenm@msu.edu
Key words: transition cow, glucose infusion, dietary protein, starch concentration

\section{INTRODUCTION}

The transition period is widely recognized as the most critical period in the lactation cycle of dairy cattle, and it is especially marked by suppressed DMI and a period of negative energy balance. Interest in understanding the mechanisms of feed intake around parturition is great due to the association of depressed feed intake with costly health disorders such as ketosis, hepatic lipidosis, and displaced abomasum. The hepatic oxidation of fuels in the liver was proposed as a mechanism for the control of feed intake and is broadly referred to as the hepatic oxidation theory (HOT; Allen et al., 2009). Plasma insulin concentration is low during the transition period (Douglas et al., 2006) and, combined with insulin resistance of peripheral tissues (Bell and Bauman, 1997), leads to increased lipid mobilization as NEFA. The liver takes up circulating plasma NEFA, and acetyl CoA is produced by $\beta$-oxidation. Oxidation of acetyl CoA within a meal from propionate influx produces ATP, generating a satiety signal according to the hepatic oxidation theory, decreasing meal size and subsequently feed intake in cows in the postpartum period (Allen et al., 2009). In addition, the hypophagic effects of propionate increase with increasing hepatic acetyl CoA concentration in postpartum cows (Stocks and Allen, 2012, 2013).

Larsen and Kristensen (2009b) infused glucose into the abomasum of cows for $29 \mathrm{~d}$ after calving to determine if glucose was limiting milk production in early lactation. Unexpectedly, infusion prevented the normal postpartum increase in DMI and milk yield. We speculate that the suppression of DMI was caused by increased hepatic oxidation of acetyl CoA within the timeframe of meals. Increasing glucose availability by glucose infusion decreased gluconeogenesis from propionate and other glucose precursors in lactating cows (Thompson et al., 1975), and elevated liver acetyl CoA concentration from $\beta$-oxidation decreases conversion of pyruvate to acetyl CoA by inhibiting pyruvate dehydro- 
genase complex (PDC; Roche et al., 2001). Repletion of tricarboxylic acid intermediates during meals likely increases their pool size to a greater extent when gluconeogenesis is downregulated and PDC is inhibited, enhancing oxidation of acetyl CoA within meals, causing satiety sooner (Allen et al., 2009).

In a subsequent paper using liver flux data from the same study, Larsen and Kristensen (2009a) determined that essential AA may have been limiting milk yield in early lactation. The diet offered to the cows in that study contained only $15.6 \%$ CP. Dairy cows are in a negative nitrogen balance for several weeks following parturition (Bell et al., 2000), and milk yield increases quadratically with increasing dietary $\mathrm{CP}$ concentration (NRC, 2001). If dietary protein limited milk yield in the cows infused with glucose by Larsen and Kristensen (2009a), use of glucose for lactose synthesis might have been limited, thus decreasing glucose demand, increasing plasma glucose and insulin concentrations, and initiating the cascade that prevented the expected increase in DMI following calving.

Objectives of this study were to determine if low dietary $\mathrm{CP}$ and high dietary starch concentration limit milk yield of cows in the immediate postpartum period, and to determine if a diet with high dietary protein and low starch concentrations would attenuate the increase in plasma glucose and insulin concentrations by glucose infusion and allow greater feed intake. We hypothesized that a high protein, low starch diet would increase milk yield, resulting in increased glucose demand, limiting the increase in plasma glucose and insulin concentrations with glucose infusion and the subsequent buildup of tricarboxylic acid cycle intermediates available to oxidize acetyl CoA. This would decrease satiety and increase DMI.

\section{MATERIALS AND METHODS}

Experimental procedures were approved by the Institutional Animal Care and Use Committee at Michigan State University. The study was conducted from June 25 to September 18, 2011.

\section{Animals, Experimental Design, and Treatments}

Twenty-four multiparous Holstein cows from the Michigan State University Dairy Field Laboratory were assigned randomly to block and treatment on the day of calving in a randomized complete block design experiment with a $2 \times 2$ factorial arrangement of treatments. Blocking criteria were BCS (within 1 unit) and previous lactation 305-d mature-equivalent milk production (within $4,500 \mathrm{~kg}$ ). Treatments were continuous intrajugular drip infusion of glucose (GI; $1 \mathrm{~kg}$ of glucose/d as $4 \mathrm{~L} / \mathrm{d}$ of $25 \% \mathrm{wt} / \mathrm{vol}$ dextrose in water) or isotonic saline (SI; $4 \mathrm{~L}$ of $0.9 \% \mathrm{NaCl}$ ), and isoenergetic diets containing $13.9 \% \mathrm{CP}$ and $29.6 \%$ starch (high starch, low protein, HSLP), or $18.3 \% \mathrm{CP}$ and $22.3 \%$ starch (high protein, low starch, HPLS). Both diets were $\sim 33.5 \% \mathrm{NDF}$, and $29.6 \%$ forage NDF. The $\mathrm{CP}$ and starch concentration of diets were adjusted by substituting soybean meal for dry ground corn (Table 1). Other diet ingredients were corn silage, grass hay, wheat straw, SoyPlus (West Central Soy, Ralston, IA), and a mineral and vitamin mix (Table 1). Ingredients and nutrient composition of the prepartum diets are listed in Table 2. Treatments were initiated at $1200 \mathrm{~h}$ at the first scheduled feeding following parturition and lasted $12 \mathrm{~d}$. Infusion bags were replaced every $6 \mathrm{~h}$ at 0600, 1200, 1800, and 2400 h daily.

Cows were fitted with indwelling catheters in each jugular vein $4 \pm 3$ d before expected calving date. Five milliliters of lidocaine hydrochloride was administered intradermally at the catheter insertion point. A stab incision was made with a \#15 scalpel blade, and a presterilized 10-gauge needle was inserted into the jugular vein. Presterilized indwelling polypropylene catheters $(0.24 \mathrm{~cm}$ o.d. $\times 0.17 \mathrm{~cm}$ i.d. tubing, MRE 085, Braintree Scientific, Braintree, MA) were inserted into the vein through the needle until approximately $30 \mathrm{~cm}$ of tubing was inside the jugular vein. Patency of catheters was checked throughout the infusion period.

\section{Data and Sample Collection}

Throughout the experiment, cows were housed in tiestalls and fed once daily at $1200 \mathrm{~h}$ at $115 \%$ of expected intake. Cows were blocked from feed from 1000 to $1200 \mathrm{~h}$ daily, and the amount of feed offered and orts were weighed for each cow daily. Samples of all dietary ingredients and orts (12.5\%) were collected daily. Dietary ingredients were composited weekly throughout the experiment, and orts for each cow were composited for the 12-d treatment period. Feeding behavior was monitored continuously for $22 \mathrm{~h}$ daily for each cow while cows had access to feed (1200 to $1000 \mathrm{~h}$ ) by a computerized data acquisition system (Dado and Allen, 1993). Data of feed disappearance and voluntary water consumption were recorded for each cow every $5 \mathrm{~s}$, and meal frequency, meal size, meal length, intermeal interval, drinking bouts, and water intake were calculated.

Cows were milked twice daily in their stalls at 0530 and $1700 \mathrm{~h}$. Milk yield was recorded daily at each milking, and milk samples were collected at each milking on $\mathrm{d} 4,8$, and 12 . Body weight was measured once at the beginning and conclusion of treatment administration, and BCS was measured $4 \pm 3 \mathrm{~d}$ before calving and at 
Table 1. Ingredients and nutrient composition of experimental diets

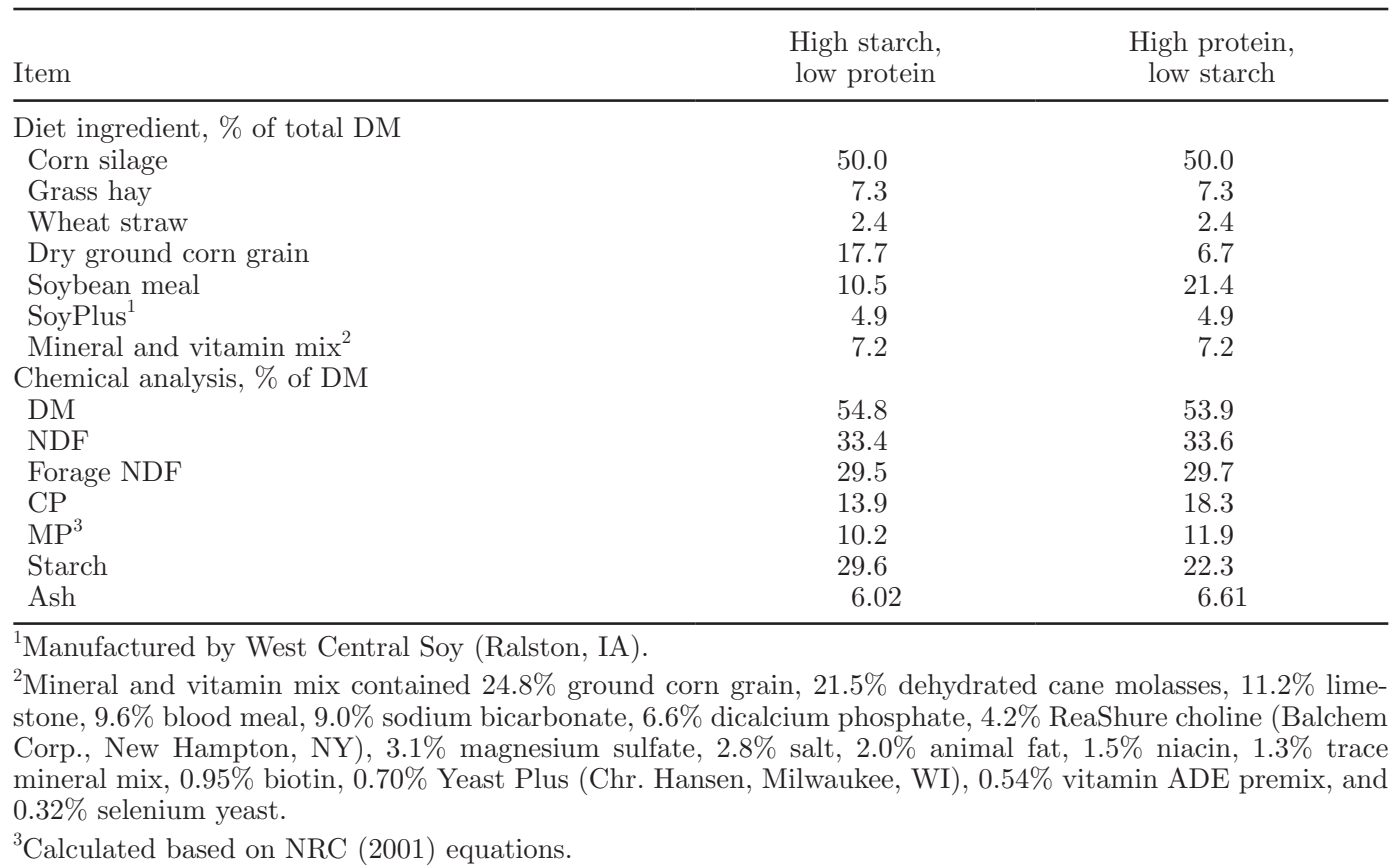

the conclusion of treatment by 3 trained investigators, where $1=$ thin and $5=$ fat (Wildman et al., 1982).

Blood samples were collected at $1100 \mathrm{~h}$ on d 0 before treatment initiation and on $\mathrm{d} 2,4,6,8,10$, and 12 . Blood was sampled from coccygeal vessels and collected into 3 evacuated tubes, 2 containing $\mathrm{K}_{2}$ EDTA and 1 containing potassium oxalate with $\mathrm{NaF}$ as a glycolytic inhibitor. Tubes were centrifuged at $3,000 \times g$ for 15 min at $5{ }^{\circ} \mathrm{C}$ immediately after sample collection, and plasma was harvested and frozen at $-20^{\circ} \mathrm{C}$ until analysis. A portion of the samples containing $\mathrm{K}_{2}$ EDTA were preserved with benzamidine ( $0.05 M$ final concentration) to reduce glucagon proteolysis.

Liver samples were collected between 1000 and $1200 \mathrm{~h}$ on $\mathrm{d} 0$ before treatment initiation and on $\mathrm{d}$ 6 and 12 for analysis of triglyceride content. Local anesthetization with $2 \%$ lidocaine hydrochloride was administered and then a 14-gauge biopsy instrument was inserted between the 11th and 12th ribs on a line between the olecranon and the tuber coxae on the right side. Five samples weighing approximately $20 \mathrm{mg}$ each were collected. Samples were immediately (within $5 \mathrm{~s}$ ) flash frozen in liquid nitrogen and stored on dry ice for transportation. Samples were promptly stored at $-80^{\circ} \mathrm{C}$ until further analysis.

\section{Sample Analysis}

Diet ingredients and orts were dried in a $55^{\circ} \mathrm{C}$ forcedair oven for $72 \mathrm{~h}$ and analyzed for DM concentration. All samples were ground with a Wiley mill (1-mm screen;
Arthur H. Thomas, Philadelphia, PA). Samples were analyzed for ash, NDF, CP, and starch. Ash concentration was determined after $5 \mathrm{~h}$ of oxidation at $500^{\circ} \mathrm{C}$ in a muffle furnace. Concentrations of NDF were determined according to Mertens (2002). Crude protein was measured according to Hach et al. (1987). Starch was measured by an enzymatic method (Karkalas, 1985)

Table 2. Ingredients and nutrient composition of the prepartum diet

\begin{tabular}{lr}
\hline Item & Value \\
\hline Diet ingredient, \% of total DM & \\
Corn silage & 42.5 \\
Grass hay & 25.4 \\
Dry ground corn grain & 3.6 \\
Soybean meal & 14.7 \\
SoyChlor & 1.5 \\
Mineral and vitamin mix ${ }^{2}$ & 12.2 \\
Chemical analysis, \% of DM & 39.5 \\
NDF & 14.1 \\
CP & 20.0 \\
Starch & 7.6 \\
Ash & \\
Calculated nutrient content, \% of total DM & 1.08 \\
Ca & 0.88 \\
K & 0.43 \\
Mg & 0.77 \\
Cl & -8.9 \\
\hline
\end{tabular}

${ }^{1}$ Manufactured by West Central Soy (Ralston, IA).

${ }^{2}$ Mineral and vitamin mix contained $36.1 \%$ SoyChlor (West Central Soy), $35.8 \%$ ground corn grain, $8.3 \%$ limestone, $6.6 \%$ ReaShure choline (Balchem Corp., New Hampton, NY), 5.4\% dicalcium phosphate, $2.5 \%$ magnesium sulfate, $1.2 \%$ Yeast Plus (Chr. Hansen, Milwaukee, WI), $1.1 \%$ salt, $1.1 \%$ niacin, $0.84 \%$ biotin, $0.50 \%$ vitamin $\mathrm{ADE}$ premix, $0.40 \%$ trace mineral premix, and $0.18 \%$ selenium yeast. 
after samples were gelatinized with sodium hydroxide; glucose concentration was measured with a glucose oxidase method (Glucose kit \#510, Sigma Chemical Co., St. Louis, MO) and absorbance was determined with a microplate reader (SpectraMax Plus 384, Molecular Devices Corp., Sunnyvale, CA). Concentrations of all nutrients except DM were expressed as percentages of $\mathrm{DM}$ determined by drying at $105^{\circ} \mathrm{C}$ in a forced-air oven for more than $8 \mathrm{~h}$.

Plasma samples were analyzed colorimetrically with a microplate reader (SpectraMax Plus 384, Molecular Devices Corp.) to determine the plasma concentrations of metabolites. A glucose oxidase method was used to determine plasma glucose concentration (Sigma Chemical Co.), and a commercial kit was used for determination of plasma NEFA (HR Series NEFA-HR 2, Wako Chemicals USA, Richmond, VA) and BHBA (Procedure \#2440, Stanbio Laboratory, Boerne, TX). An ELISA kit was used to determine concentration of plasma insulin (kit no. 10-1201-01, Mercodia, Uppsala, Sweden). Plasma glucagon concentration was determined by a RIA kit (kit no. GL-32K, Linco Research Inc., St. Charles, MO).

Milk yield recorded at both milkings were summed for a daily total. Milk samples were analyzed for fat, true protein, lactose, SCC, and MUN using infrared spectroscopy by Michigan DHIA (East Lansing). Daily yields of ECM and 3.5\% FCM (Dairy Records Management Systems, 2011), as well as milk components, were calculated using milk yield and component concentrations for each milking on respective days. Gross feed conversion efficiency was calculated by dividing milk yield by DMI.

\section{Statistical Analysis}

Using the MIXED procedure of SAS (version 9.2, 2008; SAS Institute Inc., Cary, NC), ANOVA was conducted using a randomized block design with repeated measures and an autoregressive covariance structure selected based upon the Bayesian information criterion. Block and cow were included as random effects. The effect of treatments on metabolic and milk responses and feeding behavior were analyzed with the following linear model:

$$
\begin{gathered}
Y_{i j m}=\mu+B_{i}+C\left(B_{i} G_{k} P_{1}\right)_{j}+G_{k}+P_{1}+G_{k} P_{1} \\
+T_{m}+G_{k} T_{m}+P_{1} T_{m}+G_{k} P_{1} T_{m}+J+e_{i j m},
\end{gathered}
$$

where $\mathrm{Y}_{\mathrm{ijm}}=$ the response variable; $\mu=$ overall mean; $\mathrm{B}_{\mathrm{i}}=$ random effect of block ( $\mathrm{i}=1$ to 6$) ; \mathrm{C}\left(\mathrm{B}_{\mathrm{i}} \mathrm{G}_{\mathrm{k}} \mathrm{P}_{1}\right)_{\mathrm{j}}=$ random effect of cow ( $\mathrm{j}=1$ to 4$)$ within block and infusion and dietary treatments; $\mathrm{G}_{\mathrm{k}}=$ fixed effect of infu- sion treatment ( $\mathrm{k}=1$ to 2$) ; \mathrm{P}_{1}=$ fixed effect of dietary treatment $(\mathrm{l}=1$ to 2$) ; \mathrm{T}_{\mathrm{m}}=$ fixed effect of time $(\mathrm{m}=1$ to 12$) ; \mathrm{G}_{\mathrm{k}} \mathrm{P}_{1}=$ interaction of infusion and diet; $\mathrm{G}_{\mathrm{k}} \mathrm{T}_{\mathrm{m}}=$ interaction of infusion and time; $\mathrm{P}_{1} \mathrm{~T}_{\mathrm{m}}=$ interaction of diet and time; $\mathrm{G}_{\mathrm{k}} \mathrm{P}_{1} \mathrm{~T}_{\mathrm{m}}=3$-way interaction of infusion, diet, and time; $\mathrm{J}=$ random effect of Julian date; and $\mathrm{e}_{\mathrm{ijm}}=$ residual. Julian date was included to account for variation from individual day effects.

Effects of treatment on BW and BCS change, and cumulative DMI and milk yield were analyzed using a linear model without repeated measures:

$$
\begin{aligned}
Y_{i j}=\mu+ & B_{i}+C\left(B_{i} G_{k} P_{1}\right)_{j}+G_{k}+P_{1} \\
& +G_{k} P_{l}+J+e_{i j} .
\end{aligned}
$$

Treatment effects were declared at $P<0.05$ and tendencies for treatment effects at $P<0.10$. Interactions were declared significant at $P<0.10$ and tendencies for interactions at $P<0.15$.

\section{RESULTS}

\section{Feed Intake and Feeding Behavior}

Infusion and diet interacted to affect cumulative DMI $(P=0.04)$; GI decreased cumulative DMI when HPLS was fed (164 vs. $197 \mathrm{~kg}$ ) but not when HSLP was fed (194 vs. $190 \mathrm{~kg}$; Table 3). Similarly, a tendency existed for an interaction of infusion and diet on daily DMI $(P=0.12)$ whereby GI decreased DMI by 2.8 $\mathrm{kg}$ when HPLS was fed (13.6 vs. $16.4 \mathrm{~kg})$, but did not affect DMI with HSLP (16.4 vs. $15.9 \mathrm{~kg}$; Table 3$)$. Infusion, diet, and time interacted for meal size $(P=0.07)$, whereby meal size increased more slowly over time for GI-HPLS compared with the other treatments (Figure 1). Infusion, diet, and time also interacted to affect meal frequency $(P=0.1)$ and meal length $(P=0.13)$, whereby the response across time varied among the 4 treatments. Infusion and diet interacted for meal size $(P=0.14)$; GI decreased meal size $0.31 \mathrm{~kg}$ for HPLS $(1.21$ vs. $1.52 \mathrm{~kg}$ ) but not for HSLP (1.55 vs. 1.49 ; Table $3)$. Infusion and diet also interacted for meal length $(P$ $=0.10$ ); GI decreased meal length for HPLS (24.5 vs. $28.4 \mathrm{~min}$ ) but increased meal length for HSLP (27.7 vs. 24.5 min; Table 3). A tendency for an interaction of infusion and time existed for meal interval $(P=0.12)$ because the response across time was different among the 4 treatments.

Infusion and time interacted to affect water intake $(P$ $=0.07)$; SI increased water intake over time. Accordingly, SI increased water intake $22.4 \%$ (76.5 vs. 62.5 $\mathrm{L} / \mathrm{d} ; P<0.01$; Table 3 ) and increased the number of drinking bouts $30.7 \%$ compared with GI (14.9 vs. 11.4; 


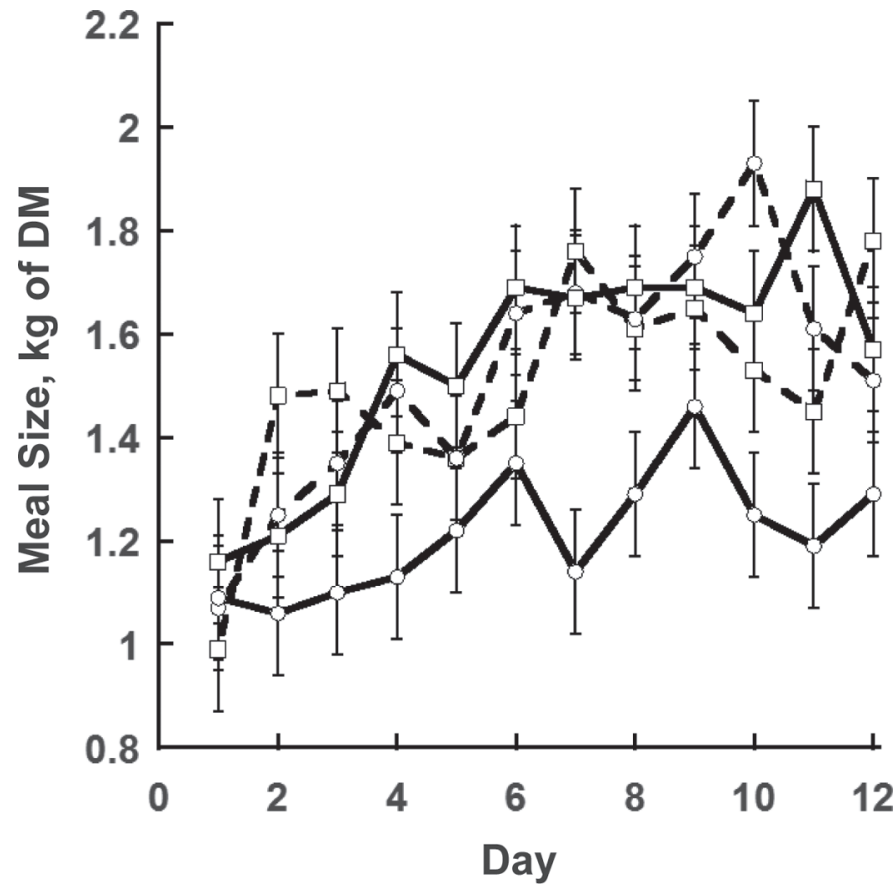

Figure 1. Interaction of infusion, diet, and time on meal size $(P=$ 0.07 ; SEM $=0.12 \mathrm{~kg}$ of DM) for SI-HSLP $(\square,---)$, SI-HPLS $(\bigcirc,---)$, GI-HSLP $(\square,-)$, and GI-HPLS $(O,-)$. SI = isotonic saline infusion; $\mathrm{GI}=$ glucose infusion; HSLP $=$ high starch, low CP; HPLS $=$ high $\mathrm{CP}$, low starch.

$P<0.01$; Table 3 ). The HPLS diet increased the number of drinking bouts per day $22.9 \%$ compared with HSLP (14.5 vs. $11.8 ; P=0.02$; Table 3 ) but had no effect on water intake $(P=0.57)$.

\section{Milk Production and Components}

Glucose infusion increased cumulative milk yield 39 $\mathrm{kg} / 12$ d compared with SI (455 vs. $416 \mathrm{~kg} ; P=0.01$; Table 4$)$ but infusion and diet interacted $(P=0.02)$; GI increased milk yield $18.7 \%$ for HSLP (469 vs. 395 $\mathrm{kg}$ ) but had no effect for HPLS (442 vs. $438 \mathrm{~kg}$; Table 4). Similar to cumulative milk yield, GI numerically increased daily milk yield $2.9 \mathrm{~kg}$ compared with SI $(37.9$ vs. $35.0 \mathrm{~kg} / \mathrm{d} ; P=0.08$; Table 4$)$ with a tendency for an interaction of treatments for daily milk yield $(P=0.12)$, whereby GI increased milk yield $5.4 \mathrm{~kg} / \mathrm{d}$ compared with SI (38.9 vs. $33.5 \mathrm{~kg} / \mathrm{d}$ ) for HSLP but had no effect for HPLS (36.8 vs. $36.5 \mathrm{~kg} / \mathrm{d}$; Table 4). Infusion, diet, and time interacted to affect daily milk yield $(P=0.08)$; SI-HSLP decreased milk yield during the first $6 \mathrm{~d}$ of treatment and GI-HSLP increased milk yield in the last $6 \mathrm{~d}$ of treatment (Figure 2). Glucose infusion increased feed efficiency compared with SI (2.54 vs. 2.18; $P<0.01$; Table 4 ), and HPLS increased feed conversion efficiency compared with HSLP (2.48 vs. $2.22 ; P=0.03$; Table 4 ).

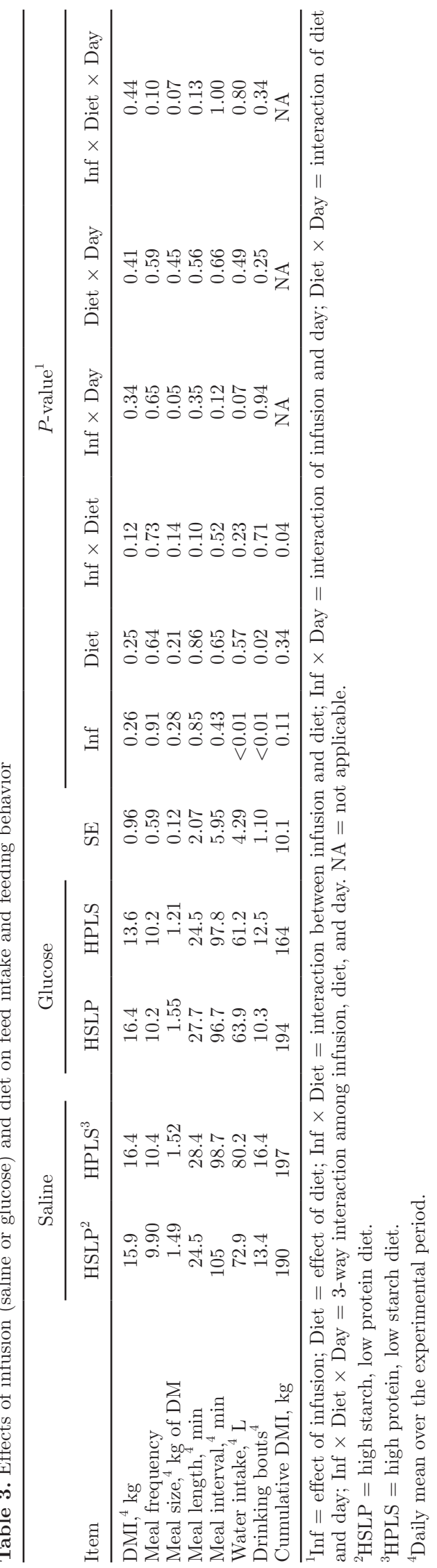


The HPLS diet, compared with HSLP, increased milk fat concentration (5.71 vs. $4.72 \% ; P<0.01$; Table 4 ), milk fat yield (2.13 vs. $1.78 \mathrm{~kg} / \mathrm{d} ; P<0.01$; Table 4$)$, and FCM (50.9 vs. $45.1 \mathrm{~kg} / \mathrm{d} ; P=0.02$; Table 4$)$, and tended to increase ECM ( 49.8 vs. $45.2 \mathrm{~kg} / \mathrm{d} ; P=0.06$; Table 4). Glucose infusion decreased milk fat concentration (4.84 vs. $5.59 \% ; P=0.01$; Table 4 ) but did not affect milk fat yield compared with SI $(P=0.32$; Table 4). Treatment did not affect protein yield, but GI decreased protein concentration compared with SI (3.27 vs. $3.50 \% ; P=0.02$; Table 4 ). Glucose infusion, compared with SI, increased lactose concentration (4.78 vs. $4.59 \% ; P<0.01$; Table 4$)$ and tended to increase lactose yield (1.87 vs. $1.69 \mathrm{~kg} / \mathrm{d} ; P=0.08$; Table 4 ). The HPLS diet doubled MUN concentration compared with HSLP (19.0 vs. $9.31 \mathrm{mg} / \mathrm{dL} ; P<0.01$; Table 4). Treatment did not affect SCC (Table 4).

\section{Plasma Metabolites and Hormones, Liver Triglyceride, and Body Condition Loss}

Diet and infusion treatments interacted to affect plasma glucose concentration $(P=0.07)$; GI increased glucose concentration to a greater extent for HPLS (60.1 vs. $42.5 \mathrm{mg} / \mathrm{dL}$ ) than for HSLP (59.9 vs. 51.6 $\mathrm{mg} / \mathrm{dL}$; Table 5). Glucose infusion increased plasma glucose concentration $27.7 \%$ compared with SI (60 vs. $47 \mathrm{mg} / \mathrm{dL} ; P<0.01$; Table 5), and HSLP numerically increased plasma glucose $8.8 \%$ compared with HPLS $(55.8$ vs. $51.3 \mathrm{mg} / \mathrm{dL} ; P=0.08$; Table 5$)$. Infusion and time interacted to affect plasma insulin concentration $(P<0.01$; Table 5); GI increased plasma insulin more over time compared with SI. Accordingly, GI increased plasma insulin concentration compared with SI (0.53 vs. $0.18 \mu \mathrm{g} / \mathrm{L} ; P<0.01$; Table 5). Glucose infusion decreased plasma glucagon concentration $17.8 \%$ compared with SI (93.1 vs. $113.2 \mathrm{pg} / \mathrm{mL} ; P=0.01$; Table 5) but there was an interaction of infusion and time $(P<$ 0.01 ) whereby GI increased plasma glucagon less over time compared with SI. Infusion of glucose increased the insulin:glucagon ratio (5.77 vs. $1.60 ; P<0.01$; Table 5) and the ratio became greater over time for GI than for SI (interaction $P<0.01$ ).

Infusion treatments also interacted with time to affect plasma NEFA concentration $(P<0.01$; Table 5) and plasma BHBA concentration $(P<0.01$; Table 5$)$; plasma NEFA and BHBA increased over time for SI, whereas GI prevented an increase in concentration of both metabolites. Glucose infusion compared with SI decreased plasma NEFA concentration $46.5 \%$ (724 vs. $1,354 \mu \mathrm{Eq} / \mathrm{L} ; P<0.01$; Table 5), plasma BHBA concentration $52.3 \%$ ( 7.2 vs. $15.1 \mathrm{mg} / \mathrm{dL} ; P<0.01$; Table 5 ), and liver triglyceride concentration $49.7 \%$ (3.16 vs. $6.28 \mathrm{mg} / \mathrm{g}$ of wet liver; $P<0.01$; Table 5). Despite de- creased plasma NEFA and BHBA and liver triglyceride for GI, infusion did not affect BCS change $(P=0.25$; Table 6$)$ or BW change $(P=0.16$; Table 6$)$.

The HPLS diet, compared with HSLP, tended to increase BCS loss $(-0.81$ vs. -0.65 BCS units $/ 12 \mathrm{~d}$; $P=0.06)$, but treatment did not affect BW change (Table 6). The increased BCS loss for HPLS resulted in increased plasma concentrations of NEFA by $32.3 \%$ $(1,184$ vs. $895 \mu \mathrm{Eq} / \mathrm{L} ; P=0.01$; Table 5$)$ and BHBA by $34.4 \%$ (12.1 vs. $9.0 \mathrm{mg} / \mathrm{dL} ; P=0.02$; Table 5 ) for HPLS compared with HSLP. Furthermore, HPLS increased hepatic triglyceride concentration $39.6 \%$ (5.71 vs. $3.56 \mathrm{mg} / \mathrm{g}$ of wet liver; $P=0.03$; Table 5 ) compared with HSLP.

\section{DISCUSSION}

Objectives of this study were to determine if the HSLP diet would limit milk yield of cows in the immediate postpartum period and to determine if the HPLS diet would allow greater milk yield, thus creating greater glucose demand, attenuating the increase in plasma glucose and insulin concentrations by GI, and allowing greater feed intake. Contrary to our hypothesis, HPLS decreased DMI with GI. Dry matter intake is a function of meal size and meal frequency, and the reduction in DMI for GI-HPLS occurred because of a reduction in mean meal size over time for GI-HPLS, with no effect on meal frequency compared with GIHSLP. The reduction in meal size indicates that satiety was increased within the timeframe of meals. Despite the reduction in intake for GI-HPLS, the present study failed to elicit a similar response to that observed by Larsen and Kristensen (2009b), in which abomasal glucose infusion reduced mean DMI by $6.2 \mathrm{~kg} / \mathrm{d}$ over the 29-d infusion. In that study, GI increased plasma insulin concentration 2- to 3 -fold, likely decreasing gluconeogenesis and possibly allowing tricarboxylic acid intermediates to accumulate, causing satiety by enhancing hepatic oxidation of acetyl $\mathrm{CoA}$, consistent with HOT (Allen et al., 2009). Hyperinsulinemic-euglycemic clamps quadrupled plasma insulin concentration and decreased feed intake $33 \%$ in fresh cows (Leury et al., 2003). In ruminants, a reduction in hepatic gluconeogenesis might force propionate to pursue a different biochemical pathway than that for glucose synthesis; glucose infusion increased plasma insulin concentration and decreased propionate conversion to glucose in lactating cows (Thompson et al., 1975). Propionate can be converted to pyruvate and then to acetyl CoA by PDC; however, this route is likely reduced for cows in the early postpartum period that have high concentrations of acetyl CoA from $\beta$-oxidation of NEFA because acetyl CoA inhibits PDC (Roche et al., 2001). Pro- 


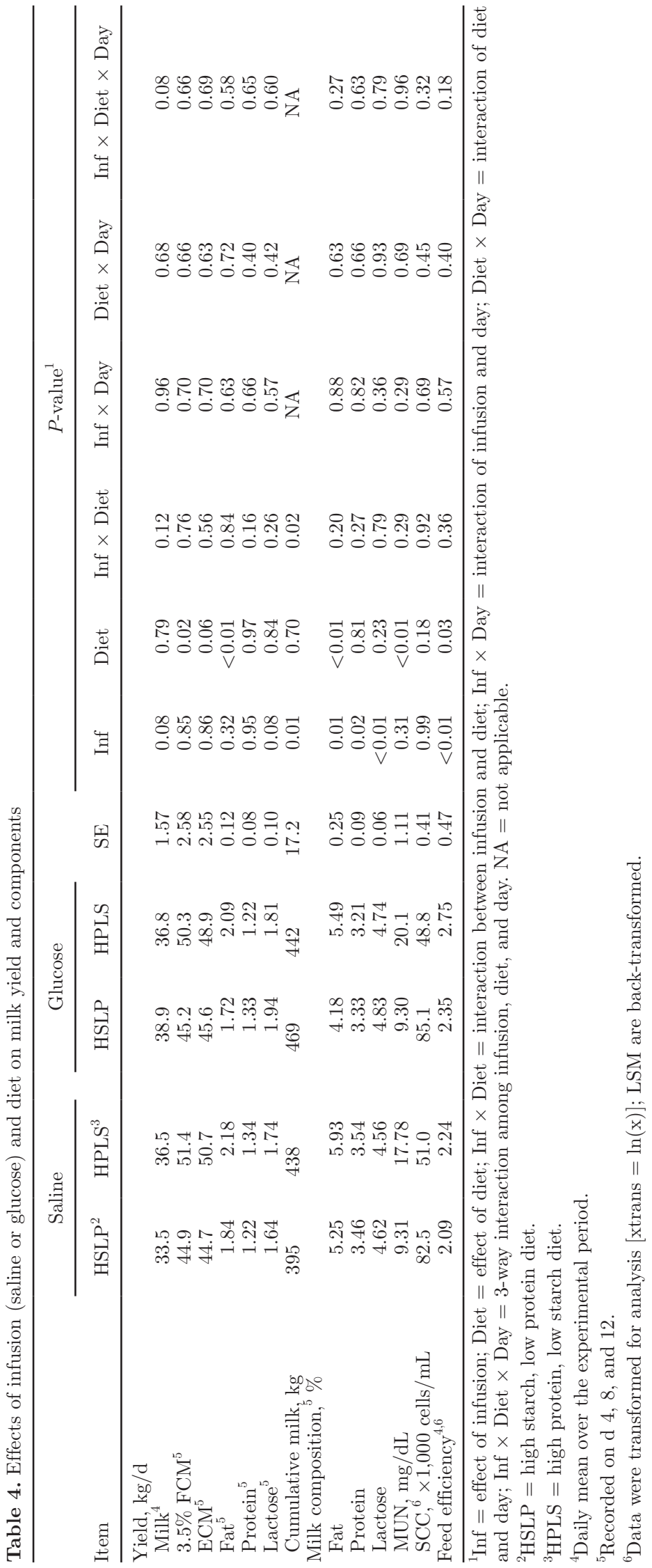




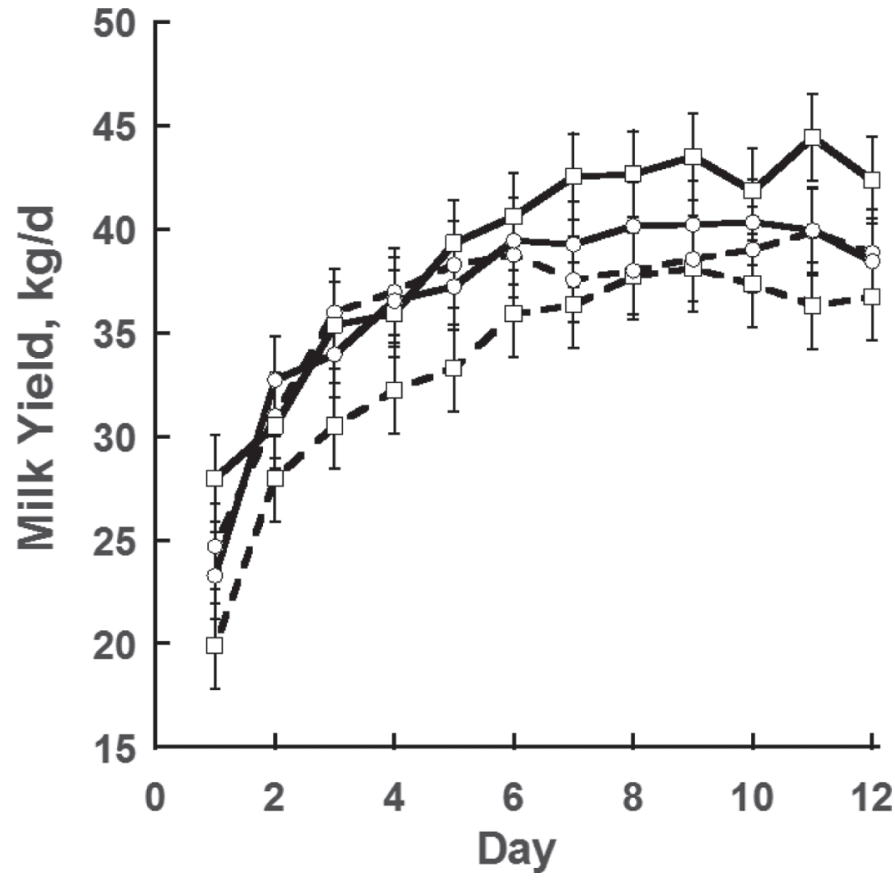

Figure 2. Interaction of infusion, diet, and time on milk yield ( $P$ $=0.08 ; \mathrm{SEM}=1.57 \mathrm{~kg} / \mathrm{d})$ for SI-HSLP $(\square,---)$, SI-HPLS $(\bigcirc,---)$, GI-HSLP $(\square,-)$, and GI-HPLS $(\bigcirc,-)$. SI = isotonic saline infusion; $\mathrm{GI}=$ glucose infusion; HSLP $=$ high starch, low CP; HPLS $=$ high CP, low starch.

pionate flux to the liver increases greatly during meals (Benson et al., 2002), and propionate supply in excess of the enzymatic capability to convert it to glucose will result in the buildup of tricarboxylic acid cycle intermediates. These intermediates provide an entry point at the citrate synthase reaction for acetyl CoA into the tricarboxylic acid cycle, producing ATP and causing satiety. Stocks and Allen $(2012,2013)$ demonstrated the effect of propionate-stimulated oxidation of acetyl CoA on DMI by showing that hypophagic effects of propionate were enhanced with greater hepatic acetyl CoA concentration across cows.

In the present study, greater lipid mobilization by the HPLS diet combined with elevated glucose and insulin concentrations from GI might have caused the reduction in meal size and feed intake in the GI-HPLS cows. If HPLS increased the supply of acetyl CoA to be oxidized while GI decreased gluconeogenesis from propionate, propionate flux within a meal could have increased the tricarboxylic acid intermediates and increased the rate of oxidation of acetyl $\mathrm{CoA}$ within meals. Over-conditioned cows at parturition generally have greater BW loss postpartum, potentially contributing to the pool of hepatic acetyl CoA. Ewes fed to gain weight during gestation weighed significantly more at parturition and had numerically greater weight loss postpartum (Rutter and Manns, 1986). Interestingly,

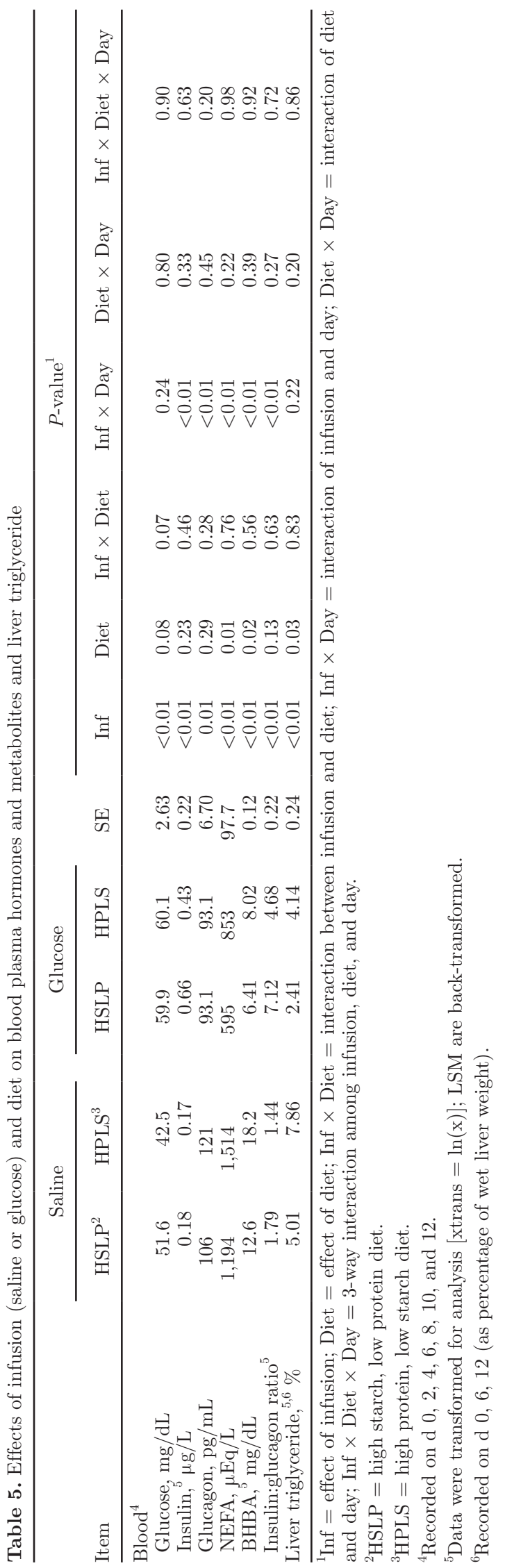

Journal of Dairy Science Vol. 96 No. 11, 2013 
Table 6. Effects of infusion (saline or glucose) and diet on BCS and BW loss

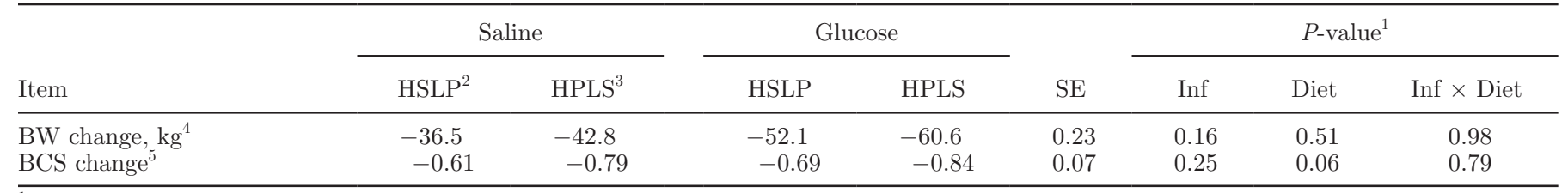

${ }^{1}$ Inf $=$ effect of infusion; Diet $=$ effect of diet; Inf $\times$ Diet $=$ interaction between infusion and diet.

${ }^{2} \mathrm{HSLP}=$ high starch, low protein diet.

${ }^{3} \mathrm{HPLS}=$ high protein, low starch diet.

${ }^{4}$ Recorded on d 0 and 12; data were transformed for analysis [xtrans $=\ln (\mathrm{x})$ ]; LSM are back-transformed.

${ }^{5}$ Recorded on $\mathrm{d}(-4 \pm 3)$ and 12 .

the ewes that weighed more at parturition experienced a drastic reduction in intake postpartum when intrajugular glucose infusion was administered compared with ewes that did not gain weight during gestation. A buildup of tricarboxylic acid cycle intermediates from a reduction of gluconeogenesis from propionate will likely increase oxidation of acetyl CoA, suppressing feed intake despite the reduction in plasma NEFA concentration. Hyperinsulinemic-euglycemic clamps decreased feed intake of fresh cows despite 37 to $71 \%$ lower plasma NEFA concentrations (Butler et al., 2003; Leury et al., 2003).

Increased concentration of tricarboxylic acid intermediates from elevated plasma insulin concentration per se is uncertain because insulin might not inhibit hepatic gluconeogenesis from propionate in ruminants (Aschenbach et al., 2010). The reduction in gluconeogenesis by insulin might be from reducing hepatic uptake of other glucose precursors with little effect on propionate incorporation into glucose as observed during hyperinsulinemic-euglycemic clamps in sheep (Brockman, 1990). Consistent with this, insulin decreased glucose production from lactate, but not propionate, with hepatocyte monolayers from ruminating calves (Donkin and Armentano, 1995). In the present study, if the elevated insulin concentration by GI only decreased hepatic uptake of glucose precursors other than propionate, there might be less effect on the pool of tricarboxylic acid intermediates than if it decreased gluconeogenesis from propionate during the timeframe of meals. However, those results are in contrast to a study with lactating cows (Thompson et al., 1975) in which short-term intrajugular glucose infusion at approximately twice the infusion rate of the current experiment increased plasma insulin concentration and decreased propionate conversion to glucose by $43 \%$. Also, increased glucose demand with phlorizin treatment increased gluconeogenesis from propionate in steers (Veenhuizen et al., 1988). We previously reported that phlorizin treatment increased hepatic mRNA abundance for key regulatory gluconeogenic enzymes in lactating cows, including phosphoenolpyruvate car- boxykinase and glucose-6-phosphatase (Bradford and Allen, 2005), which would likely increase gluconeogenesis from propionate. Effects of GI on gluconeogenesis might be more complex than increased plasma insulin concentration per se, involving interactions among plasma glucose, insulin, and glucagon that were not accounted for in the ex vivo experiments and might differ for lactating cows compared with sheep. We did not measure gluconeogenesis from propionate in this experiment so we are unable to discern if gluconeogenesis from propionate was decreased by infusion of glucose, causing a buildup of tricarboxylic acid intermediates within meals.

It is unclear why the HPLS diet in this study increased lipid mobilization despite no effect of diet on plasma insulin concentration. Propionate is a major end-product of starch fermentation, and propionate increases insulin secretion (Sano et al., 1993). Therefore, it would be expected that the HSLP diet compared with the HPLS diet would produce more propionate and increase plasma insulin concentration. However, total glucose precursors provided by the 2 diets may have been similar because HPLS may have provided glucogenic AA, although this cannot be verified in the present study. The discrepancy between the increased lipid mobilization for HPLS despite the lack of a diet effect on insulin concentration may be because the sampling time for blood was $1 \mathrm{~h}$ before feeding, a time when differences in plasma insulin concentration between diets were likely the smallest (Oba and Allen, 2003a).

Plasma and ruminal ammonia concentrations were not measured in this study; however, MUN concentration increased 2-fold for cows fed HPLS, suggesting greater protein degradation in the rumen, excess AA supply, or both. The MP calculation for the diets suggests that the HPLS diet supplied more AA than HSLP. The increase in MUN concentration for HPLS is consistent with greater supply of tricarboxylic acid intermediates, enhancing hepatic oxidation of acetyl-CoA and contributing to satiety. Infusion of ammonium with propionate interacted with additive effects to reduce DMI, possibly by supplying additional carbon skeletons 
to the tricarboxylic acid cycle in the form of fumarate produced by the urea cycle (Oba and Allen, 2003c). Besides ammonia production from deamination of AA, when AA supply exceeds AA required, glucogenic AA carbon skeletons may enter the tricarboxylic acid cycle, increasing the supply of tricarboxylic acid intermediates further, and other AA can add to the pool of acetyl CoA to be oxidized or exported as ketone bodies. We also considered that ammonium chloride decreased propionate conversion to glucose while slightly increasing $\mathrm{CO}_{2}$ production from propionate in vitro using liver cells from lactating dairy goats, suggesting greater oxidation of propionate (Aiello and Armentano, 1987). If plasma ammonia concentration increased for HPLS, resulting in decreased gluconeogenesis, this could be another possible explanation for a buildup of tricarboxylic acid cycle intermediates to oxidize acetyl CoA, reducing DMI for GI-HPLS. Intraruminal infusions of ammonium propionate increased MUN and decreased DMI in mid-lactation cows by decreasing the number of meals compared with infusions of sodium acetate, ammonium acetate, and sodium propionate (Oba and Allen, 2003c).

Feed intake was not likely influenced to a large degree by milk production because intake did not follow the same pattern as that of milk yield. We hypothesized that HPLS would increase milk yield, limiting the increase in plasma insulin concentration by GI, thus increasing feed intake. These results are inconclusive in regards to whether protein was limiting in early lactation; although SI-HSLP resulted in the lowest milk yield, GI-HSLP resulted in the greatest milk yield. These results suggest that glucose may be more limiting than protein for milk production during this period because of the increase in cumulative milk yield from glucose infusion compared with saline infusion.

The HPLS diet increased milk fat yield, and because there was only a tendency for GI to increase daily milk yield, HPLS increased milk fat concentration and FCM. Elevated lipid mobilization can cause an increase in milk fat yield during negative energy balance (Bauman and Griinari, 2003). The HPLS diet increased plasma NEFA concentration, which could have contributed to the increased milk fat. Alternatively, the HSLP diet may have altered ruminal biohydrogenation pathways, causing milk fat depression (Bauman and Griinari, 2003). The HSLP diet offered was $29.6 \%$ starch compared with the $22.3 \%$ starch concentration of the HPLS diet. Although HSLP was not considered a low forage diet, at $29.5 \%$ forage NDF, the starch concentration was high for early lactation cows and may have increased ruminal outflow of certain conjugated linoleic acid isomers, inhibiting milk fat yield. trans-10, cis-12 conjugated linoleic acid inhibits milk fat yield in dairy cows by decreasing expression of genes in the mammary gland associated with milk fat synthesis (Baumgard et al., 2002). Furthermore, milk fat depression induced by trans-10,cis-12 conjugated linoleic acid partitions energy toward fat stores by increasing the expression of lipogenic enzymes in adipose tissue (Harvatine et al., 2009). In the present study, the HSLP diet decreased milk fat yield, BCS loss, and lipid mobilization, indicating that energy may have been partitioned toward adipose tissue. Unfortunately, because milk samples were not obtained for fatty acid analysis, we are not able to confirm this.

Glucose decreased milk fat concentration, which is consistent with previous research (Al-Trad et al., 2009). This could be because of the antilipolytic effect of insulin on adipose tissue. However, the reduction in milk fat concentration and protein concentration for GI is likely the result of a dilution factor; daily milk yield tended to increase whereas milk fat yield and protein yield remained unchanged for GI.

The SI treatment increased water intake, which is consistent with infusion of salts into the rumen (Oba and Allen, 2003b). Unfortunately, no data exist with respect to the effect of water intake on the passage of ruminal liquid fractions during a drinking bout, so it remains possible that the increased water intake for SI may have altered the rumen ecosystem.

\section{CONCLUSIONS}

The GI treatment decreased cumulative DMI for cows fed the HPLS treatment. This might be attributed to the combined effects of a reduction in gluconeogenesis for GI and increased plasma NEFA concentration and tricarboxylic acid cycle intermediates for HPLS, resulting in increased oxidation of acetyl CoA within meals. The HPLS treatment increased MUN concentration, possibly through greater ruminal ammonia production, which may have decreased gluconeogenesis from propionate and increased tricarboxylic acid cycle intermediates, increasing oxidation of acetyl CoA. Additionally, elevated urea synthesis may have contributed to increased oxidation of $\mathrm{AA}$ in the urea cycle, thus increasing satiety during meals. The GI-HSLP treatment combination resulted in the greatest milk yield, whereas SI-HSLP resulted in the lowest milk yield; however, feed intake was likely not influenced to a large degree by milk yield in this study. The HPLS treatment increased plasma NEFA concentration and liver triglyceride concentration. In addition, HPLS increased yield of milk fat, possibly from the greater plasma NEFA concentration or lesser ruminal outflow of conjugated linoleic acid isomers known to inhibit milk fat yield. Future research should examine whether degree of lipid 
mobilization affects feed intake postpartum during glucose infusion.

\section{ACKNOWLEDGMENTS}

The authors thank D. G. Main, R. A. Longuski, S. E. Stocks, P. Piantoni (Department of Animal Science, Michigan State University, East Lansing), and R. E. Kreft and the staff of the Michigan State University Dairy Field Laboratory (East Lansing) for their technical assistance and support, and West Central Soy Cooperative (Ralston, IA) for donating the SoyPLUS protein supplement.

\section{REFERENCES}

Aiello, R. J., and L. E. Armentano. 1987. Gluconeogenesis in goat hepatocytes is affected by calcium, ammonia and other key metabolites but not primarily through cytosolic redox state. Comp. Biochem. Physiol. B 88:193-201.

Al-Trad, B., K. Reisberg, T. Wittek, G. B. Penner, A. Alkaassem, G. Gäbel, M. Fürll, and J. R. Aschenbach. 2009. Increasing intravenous infusions of glucose improve body condition but not lactation performance in midlactation dairy cows. J. Dairy Sci. 92:5645-5658.

Allen, M. S., B. J. Bradford, and M. Oba. 2009. Board Invited Review: The hepatic oxidation theory of the control of feed intake and its application to ruminants. J. Anim. Sci. 87:3317-3334.

Aschenbach, J. R., N. B. Kristensen, S. S. Donkin, H. M. Hammon, and G. B. Penner. 2010. Gluconeogenesis in dairy cows: The secret of making sweet milk from sour dough. IUBMB Life 62:869-877.

Bauman, D. E., and J. M. Griinari. 2003. Nutritional regulation of milk fat synthesis. Annu. Rev. Nutr. 23:203-227.

Baumgard, L. H., E. Matitashvili, B. A. Corl, D. A. Dwyer, and D. E. Bauman. 2002. trans-10, cis-12 conjugated linoleic acid decreases lipogenic rates and expression of genes involved in milk lipid synthesis in dairy cows. J. Dairy Sci. 85:2155-2163.

Bell, A. W., and D. E. Bauman. 1997. Adaptations of glucose metabolism during pregnancy and lactation. J. Mammary Gland Biol. Neoplasia 2:265-278.

Bell, A. W., W. S. Burhans, and T. R. Overton. 2000. Protein nutrition in late pregnancy, maternal protein reserves and lactation performance in dairy cows. Proc. Nutr. Soc. 59:119-126.

Benson, J. A., C. K. Reynolds, P. C. Aikman, B. Lupoli, and D E. Beever. 2002. Effects of abomasal vegetable oil infusion on splanchnic nutrient metabolism in lactating dairy cows. J. Dairy Sci. 85:1804-1814.

Bradford, B. J., and M. S. Allen. 2005. Phlorizin administration increases hepatic gluconeogenic enzyme mRNA abundance but not feed intake in late-lactation dairy cows. J. Nutr. 135:2206-2211.

Brockman, R. P. 1990. Effect of insulin on the utilization of propionate in gluconeogenesis in sheep. Br. J. Nutr. 64:95-101.

Butler, S. T., A. L. Marr, S. H. Pelton, R. P. Radcliff, M. C. Lucy, and W. R. Butler. 2003. Insulin restores GH responsiveness during lactation-induced negative energy balance in dairy cattle: Effects on expression of IGF-1 and GH receptor 1A. J. Endocrinol. 176:205-217.

Dado, R. G., and M. S. Allen. 1993. Continuous computer acquisition of feed and water intake, chewing reticular motility, and ruminal pH of cattle. J. Dairy Sci. 76:1589-1600.

Dairy Records Management Systems. 2011. DHI Glossary. Accessed Jun. 22, 2012. http://www.drms.org/PDF/materials/glossary.pdf.

Donkin, S. S., and L. E. Armentano. 1995. Insulin and glucagon regulation of gluconeogenesis in preruminating and ruminating bovine. J. Anim. Sci. 73:546-551.
Douglas, G. N., T. R. Overton, H. G. Bateman, H. M. Dann, and J. K. Drackley. 2006. Prepartal plane of nutrition, regardless of dietary energy source, affects periparturient metabolism and dry matter intake in Holstein cows. J. Dairy Sci. 89:2141-2157.

Hach, C. C., B. K. Bowden, A. B. Lopelove, and S. V. Brayton. 1987. More powerful peroxide Kjeldahl digestion method. J. AOAC 70:783-787.

Harvatine, K. J., J. W. Perfield, and D. E. Bauman. 2009. Expression of enzymes and key regulators of lipid synthesis is upregulated in adipose tissue during CLA-induced milk fat depression in dairy cows. J. Nutr. 139:849-854.

Karkalas, J. 1985. An improved enzymatic method for the determination of native and modified starch. J. Sci. Food Agric. 36:10191027

Larsen, M., and N. B. Kristensen. 2009a. Effect of abomasal glucose infusion on splanchnic amino acid metabolism in periparturient dairy cows. J. Dairy Sci. 92:3306-3318.

Larsen, M., and N. B. Kristensen. 2009b. Effect of abomasal glucose infusion on splanchnic and whole-body glucose metabolism in periparturient dairy cows. J. Dairy Sci. 92:1071-1083.

Leury, B. J., L. H. Baumgard, S. S. Block, N. Segoale, R. A. Ehrhardt, R. P. Rhoads, D. E. Bauman, A. W. Bell, and Y. R. Boisclair. 2003. Effect of insulin and growth hormone on plasma leptin in periparturient dairy cows. Am. J. Physiol. Regul. Integr. Comp. Physiol. 285:R1107-R1115.

Mertens, D. R. 2002. Gravimetric determination of amylase-treated neutral detergent fiber in feeds with refluxing in beakers or crucibles: Collaborative study. J. AOAC Int. 85:1217-1240.

NRC. 2001. Nutrient Requirements of Dairy Cattle. 7th rev. ed. Natl. Acad. Press, Washington, DC.

Oba, M., and M. S. Allen. 2003a. Effects of corn grain conservation method on feeding behavior and productivity of lactating dairy cows at two dietary starch concentrations. J. Dairy Sci. 86:174183.

Oba, M., and M. S. Allen. 2003b. Effects of intraruminal infusion of sodium, potassium, and ammonium on hypophagia from propionate in lactating dairy cows. J. Dairy Sci. 86:1398-1404.

Oba, M., and M. S. Allen. 2003c. Hypophagic effects of ammonium are greater when infused with propionate compared with acetate in lactating dairy cows. J. Nutr. 133:1100-1104.

Roche, T. E., J. C. Baker, X. Yan, Y. Hiromasa, X. Gong, T. Peng, J. Dong, A. Turkan, and S. Kasten. 2001. Distinct regulatory properties of pyruvate dehydrogenase kinase and phosphatase isoforms. Prog. Nucleic Acid Res. Mol. Biol. 70:33-75.

Rutter, L. M., and J. G. Manns. 1986. Changes in metabolic and reproductive characteristics associated with lactation and glucose infusion in the postpartum ewe. J. Anim. Sci. 63:538-545.

Sano, H., N. Hattori, Y. Todome, J. Tsuruoka, H. Takahashi, and Y. Terashima. 1993. Plasma insulin and glucagon responses to intravenous infusion of propionate and their autonomic control in sheep. J. Anim. Sci. 71:3414-3422.

Stocks, S. E., and M. S. Allen. 2012. Hypophagic effects of propionate increase with elevated hepatic acetyl coenzyme A concentration for cows in the early postpartum period. J. Dairy Sci. 95:3259-3268.

Stocks, S. E., and M. S. Allen. 2013. Hypophagic effects of propionic acid are not attenuated during a 3-day infusion in the early postpartum period in Holstein cows. J. Dairy Sci. 96:4615-4623. http://dx.doi.org/10.3168/jds.2013-6653.

Thompson, J. R., G. Weiser, K. Seto, and A. L. Black. 1975. Effect of glucose load on synthesis of plasma glucose in lactating cows. J. Dairy Sci. 58:362-370.

Veenhuizen, J. J., R. W. Russell, and J. W. Young. 1988. Kinetics of metabolism of glucose, propionate and $\mathrm{CO}_{2}$ in steers as affected by injecting phlorizin and feeding propionate. J. Nutr. 118:13661375.

Wildman, E. E., G. M. Jones, P. E. Wagner, R. L. Boman, H. F. Troutt Jr., and T. N. Lesch. 1982. A dairy cow body condition scoring system and its relationship to selected production characteristics. J. Dairy Sci. 65:495-501. 